\title{
Successive Olfactory Reversal Learning in Honeybees
}

\author{
Bernhard Komischke, ${ }^{1}$ Martin Giurfa, ${ }^{2,4}$ Harald Lachnit, ${ }^{3}$ and Dagmar Malun ${ }^{1}$ \\ ${ }^{1}$ Neurobiology, Institute of Biology, Free University of Berlin, D-14195 Berlin, Germany; ${ }^{2}$ Ethologie et Cognition Animale, Université \\ Paul-Sabatier, 31062 Toulouse cedex 04, France; ${ }^{3}$ Department of Psychology, Philipps-University of Marburg, D-35032 Marburg, Germany
}

\begin{abstract}
Honeybees Apis mellifera can associate an originally neutral odor with a reinforcement of sucrose solution. Forward pairings of odor and reinforcement enable the odor to release the proboscis extension reflex in consecutive tests. Bees can also be conditioned differentially: They learn to respond to a reinforced odor and not to a nonreinforced one. They can also learn to reverse their choice. Here we ask whether honeybees can learn successive olfactory differential conditioning tasks involving different overlapping pairs of odors. The conditioning schedules were established in order to train the animals with $3,2,1$, or 0 reversals previous to a last differential conditioning phase in which two additional reversals were present. We studied whether or not successive reversal learning is possible and whether or not learning olfactory discrimination reversals affects the solving of subsequent discrimination reversals. Therefore we compared the responses of bees that had experienced reversals with those of bees that had not experienced such reversals when both are confronted with a new reversal situation. In experiment 1 we showed that bees that had experienced three previous reversals were better in solving the final reversal task than bees with no previous reversal experience. In experiment 2, we showed that one reversal learning is enough for bees to perform better in the final reversal task. The successive different reversals trained in our experiments resemble the natural foraging situation in which a honeybee forager has to switch successively from an initial floral species to different ones. The fact that experiencing such changes seems to improve a bee's performance in dealing with further new exploited food sources has therefore an adaptive impact for the individual and for the colony as a whole.
\end{abstract}

Learning is a property exhibited by the majority of living animals. Animals can learn that an originally neutral stimulus acts as a predictor (conditioned stimulus, CS) for a biologically significant stimulus (unconditioned stimulus, US). They also learn that a different CS acts as a predictor for the absence of US. The former is called CS+; the latter is called CS-. Learning these basic associations between single stimuli define the so-called differential conditioning, which can be acquired by a great variety of animals through classical conditioning (Pavlov 1927).

Such associations are not rigid but can be reversed by experience. In reversal learning (Pavlov 1927), the animal first learns a particular discrimination and then the reinforcement contingencies are reversed. In other words, once the animal has learned to solve the first differential conditioning task, it has to learn to reverse its response to the CSs. Such reversals tend to be difficult for animals because there are negative transfer effects (e.g., the individual tends to persist in responding to the stimulus that was originally reinforced). Eventually, however, this tendency becomes weaker, and the response to the alternative stimulus becomes more frequent until it is consistently evoked.

${ }^{4}$ Corresponding author.

E-MAIL giurfa@cict.fr; FAX 33-561-556154.

Article and publication are at http://www.learnmem.org/cgi/doi/ $10.1101 / \mathrm{lm} .44602$.
In serial reversal learning, the individual learns a certain discrimination to a set criterion before the reinforcement contingencies are reversed. After that, successive reversals are performed using the same stimuli as CSs to determine if the animal reaches the criterion faster (or with fewer errors) with increasing reversal experience. Serialreversal-learning sets with the same pair of CSs have been used to assess whether or not different species exhibit qualitatively different strategies in solving this problem (for review, see Davey 1989). After extended reversal training, some animals are able to make the next reversal in the sequence in one trial. They behave as if they have mastered the abstract concept of alternation or of regular sequence. Bitterman (1975) has argued that the speed with which animals of a given species improve on reversals of this kind seems to be related to differences in "intelligence".

A possible modification of the original schedule of serial reversal learning involves successive, different overlapping pairs of CSs instead of a single pair of CSs. To differentiate this paradigm from serial reversal learning, we call it successive reversal learning. For instance, an animal may be trained to solve first an $\mathrm{A}+$ versus $\mathrm{B}-$ discrimination, then a $\mathrm{B}+$ versus $\mathrm{C}-$ discrimination, then a $\mathrm{C}+$ versus $\mathrm{D}-$, and finally a D+ versus A- discrimination. Along these consecutive four phases, the animal is first confronted with a $\mathrm{B}-\rightarrow \mathrm{B}+$ reversal, then with a $\mathrm{C}-\rightarrow \mathrm{C}+$ reversal, and then

LEARNING \& MEMORY 9:122-129 @ 3 by Cold Spring Harbor Laboratory Press ISSN1072-0502/02 \$5.00

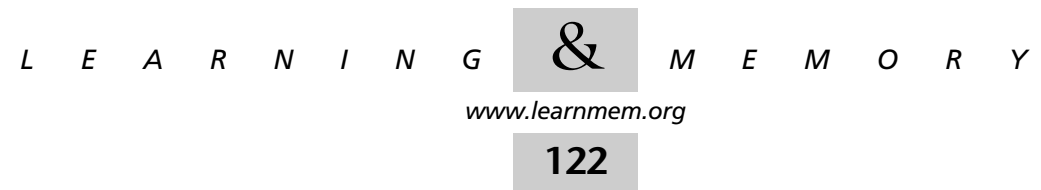


with $\mathrm{D}-\rightarrow \mathrm{D}+$ reversal and with a $\mathrm{A}+\rightarrow \mathrm{A}-$ reversal. This problem is akin to designs used to study configural (Pearce 1994; Rudy and Sutherland 1995) as opposed to elemental learning (Rescorla and Wagner 1972). As the configurallearning notion assumes that the representation of a stimulus compound is different from the simple sum of the individual representations of its components (i.e., "the whole is different from the sum of its parts"), designs such as the one described above are useful to determine whether animals learn each odor pair within a differential conditioning as an independent configuration such that it is easy to respond to the appropriate CS+ given a particular CS-. Furthermore, successive reversal learning is reminiscent of transverse patterning in which an animal has to learn three different discriminations: A+ versus $\mathrm{B}-, \mathrm{B}+$ versus $\mathrm{C}-$, and $\mathrm{C}+$ versus $\mathrm{A}-$ (Alvarado and Rudy 1992). In both cases each element appears twice, once reinforced and once nonreinforced, such that solutions based on pure elemental associative strengths are not possible. As in the case of serial reversal learning, one may ask here whether solving a first reversal improves the performance in solving further reversals. Similarly to serial reversal learning, such an improvement would be consistent with an ability called learning to learn (i.e., the fact that after having learned a new task, animals may more readily learn other related tasks).

The honeybee, Apis mellifera L, constitutes a classical model for the study of cognitive capacities (Menzel and Giurfa 2001). The honeybee is a useful model not only because of its fast learning and prolonged memory capabilities but also because it offers an excellent opportunity to study the physiological basis of such capabilities (Menzel 1985; Menzel et al. 1993; Menzel and Müller 1996; Menzel and Giurfa 2001). Olfactory conditioning in the honeybee has been extensively studied to this end (Bitterman et al. 1983; Smith 1991; Smith and Cobey 1994; Hammer and Menzel 1995; Bitterman 1996; Menzel and Müller 1996; Hammer 1997). In this paradigm, harnessed honeybees are conditioned to olfactory stimuli associated with a reinforcement of sucrose solution (Takeda 1961; Bitterman et al. 1983). When the antennae of a hungry bee are touched with sucrose solution, the animal reflexively extends its proboscis to reach out to and suck the sucrose. Odors to the antennae do not usually release such a reflex in naive animals. If an odor is presented immediately before sucrose solution (forward pairing), an association is formed which enables the odor to release the proboscis extension response (PER) in a following test. This effect is clearly associative and involves classical conditioning (Bitterman et al. 1983). Thus the odor can be viewed as the CS and sucrose solution as the reinforcing US. Differential conditioning with two odors is also possible in this frame (Bitterman et al. 1983), and reversal learning has been also demonstrated (Ben-Shahar et al. 2000; Hosler et al. 2000; Ferguson et al 2001). Serial reversal learning was studied in free-flying bees trained to colors as
CSs (Menzel 1969), but so far no attempts have been made to characterize serial and successive reversal learning in the olfactory proboscis-conditioning paradigm.

Here we ask how bees perform in successive reversal olfactory conditioning. More specifically, we studied whether or not learning olfactory discrimination reversals affects the solving of further discrimination reversals. Therefore we compared the responses of bees that had experienced reversals with those of bees that had not experienced such reversals when both are confronted with a new reversal situation.

\section{RESULTS}

\section{Experiment 1}

In this experiment we studied whether reversal learning affected the solving of further reversals in olfactory discrimination. Two different groups of 27 bees each were used. Both groups were trained along five phases of differential conditioning (Table 1). In group 1, bees were trained with three reversals. In group 2, bees had no reversal during training. Within each phase, reinforced and nonreinforced odors were given three times and in a randomized sequence. Odors used were limonene, 2-octanol, nonanone, and 2-heptanal (SIGMA). Previous experiments had shown that bees could learn and discriminate these odors equally well. The experiment was designed such that all odors were balanced with respect to their conditioning as A, B, C, and $\mathrm{D}$, with at least one bee per combination.

Bees of group 1 were first trained with an A+ versus Bdiscrimination (phase 1 ) and then with a $\mathrm{B}+$ versus $\mathrm{C}-$ discrimination (phase 2). These two phases were consecutively repeated (phases 3 and 4). In the last phase, bees were conditioned with a $\mathrm{C}+$ versus $\mathrm{A}-$ discrimination (phase 5). Thus, this group had first a $\mathrm{B}-\rightarrow \mathrm{B}+$ reversal from phase 1 to phase 2, a $\mathrm{B}+\rightarrow \mathrm{B}$ - reversal from phase 2 to phase 3 , and a second $\mathrm{B}-\rightarrow \mathrm{B}+$ reversal from phase 3 to phase 4. Like group 1, group 2 was first trained with an $\mathrm{A}+$ versus $\mathrm{B}-$ discrimination (phase 1) but was then trained with a $\mathrm{D}+$ versus $\mathrm{C}-$ discrimination (phase 2 ). These two phases were consecutively repeated (phases 3 and 4). In the last phase, bees were conditioned with a $\mathrm{C}+$ versus $\mathrm{A}-$ discrimination (phase 5). Thus, contrarily to group 1, group 2 had no reversal experience before the start of the final phase (phase 5), which was identical for both groups. We asked whether or not differing experience in reversal learn-

\begin{tabular}{cccc} 
Table 1. & Experiment 1 & & \\
\hline Group & Phase $1 / 3$ & Phase 2/4 & Phase 5 \\
\hline 1 & $\mathrm{~A}+\mathrm{B}-$ & $\mathrm{B}+\mathrm{C}-$ & $\mathrm{C}+\mathrm{A}-$ \\
2 & $\mathrm{~A}+\mathrm{B}-$ & $\mathrm{D}+\mathrm{C}-$ & $\mathrm{C}+\mathrm{A}-$ \\
\hline
\end{tabular}

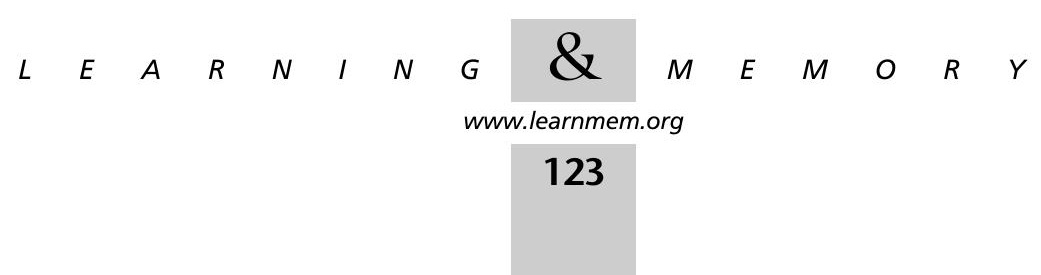


ing affects the performance in the two final reversals implicated in phase $5(\mathrm{C}-\rightarrow \mathrm{C}+$ and $\mathrm{A}+\rightarrow \mathrm{A}-$ ).

Figure 1 shows the course of responding for group 1 (upper panels) and group 2 (lower panels) throughout phase 1 to phase 5 (columns from left to right). Two preconditions have to be met before answering the question raised above. First, both groups should not differ in their ability to learn a discrimination between $\mathrm{A}+$ versus $\mathrm{B}-$, and second, they should not differ in their response to A+ (phase 3, trial 3) and $\mathrm{C}-$ (phase 4, trial 3) before the test of reversal learning $(\mathrm{A}-, \mathrm{C}+)$ in phase 5 .

The groups did not differ in their ability to learn the A+ versus $\mathrm{B}-$ discrimination. In phase 1 (Fig. 1, first column) both groups were directly comparable and showed successful response differentiation between $\mathrm{A}+$ and $\mathrm{B}-$ across trials. Starting from $\sim 40 \%$ PER in trial 1 for $\mathrm{A}+$, as well as $\mathrm{B}-$, both groups reached a comparable amount of differentiation in trial 3 . This was confirmed by a $2 \times 2$ (group $\times$ stimulus A/B) analysis of variation (ANOVA) for trial 3. The main effect stimulus was significant $\left(F_{1,52}=29.55 ; P<0.001\right)$, whereas the group $\times$ stimulus interaction was not significant $\left(F_{1,52}=1.68\right.$; NS). Also both groups showed comparable response to A+ (phase 3, trial 3) and $\mathrm{C}-$ (phase 4, trial 3) before the last reversal learning $(\mathrm{A}-, \mathrm{C}+$ ) in phase 5 . Comparing the responses to $\mathrm{A}+$ in the last trial of phase 3 and to $\mathrm{C}-$ in the last trial of phase 4 by means of ANOVA yielded $F<1$. Hence, the necessary conditions for evaluating the impact of prior reversals in phase 5 were met.

To evaluate this impact statistically, for each group we computed a score indexing the amount of reversal learning in phase 5. Reversal learning is successful if there is a decrease in responding to $\mathrm{A}-\left(\Delta_{1}=\mathrm{A}-{ }_{\text {trial } 1}-\mathrm{A}-_{\text {trial } 3}\right)$, plus an increase in responding to $\mathrm{C}+\left(\Delta_{2}=\mathrm{C}++_{\text {trial }}{ }_{3}-\mathrm{C}++_{\text {trial }}{ }_{1}\right)$. Hence, the amount of reversal learning can be indexed by $\Delta$ $\left(\Delta=\Delta_{1}+\Delta_{2}\right)$. In group 1 , in which bees had already experienced reversals, this learning score was twice as high ( $\Delta=0.741)$ as in group 2 without any prior reversal experience $(\Delta=0.37)$. This difference was statistically significant $\left(F_{1,52}=5.51 ; P<0.03\right)$. We therefore conclude that pre-experiencing reversal training with one stimulus three times (here stimulus B) improved the ability to reverse the contingencies of two other stimuli.

\section{Experiment 2}

Experiment 2 aimed at replicating this successful demonstration of successive reversal learning by reducing the number of reversal pre-experiences. Three different groups of 32 bees each were used. Groups were trained along four phases of differential conditioning (phases 1-4; see Table

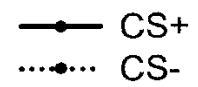

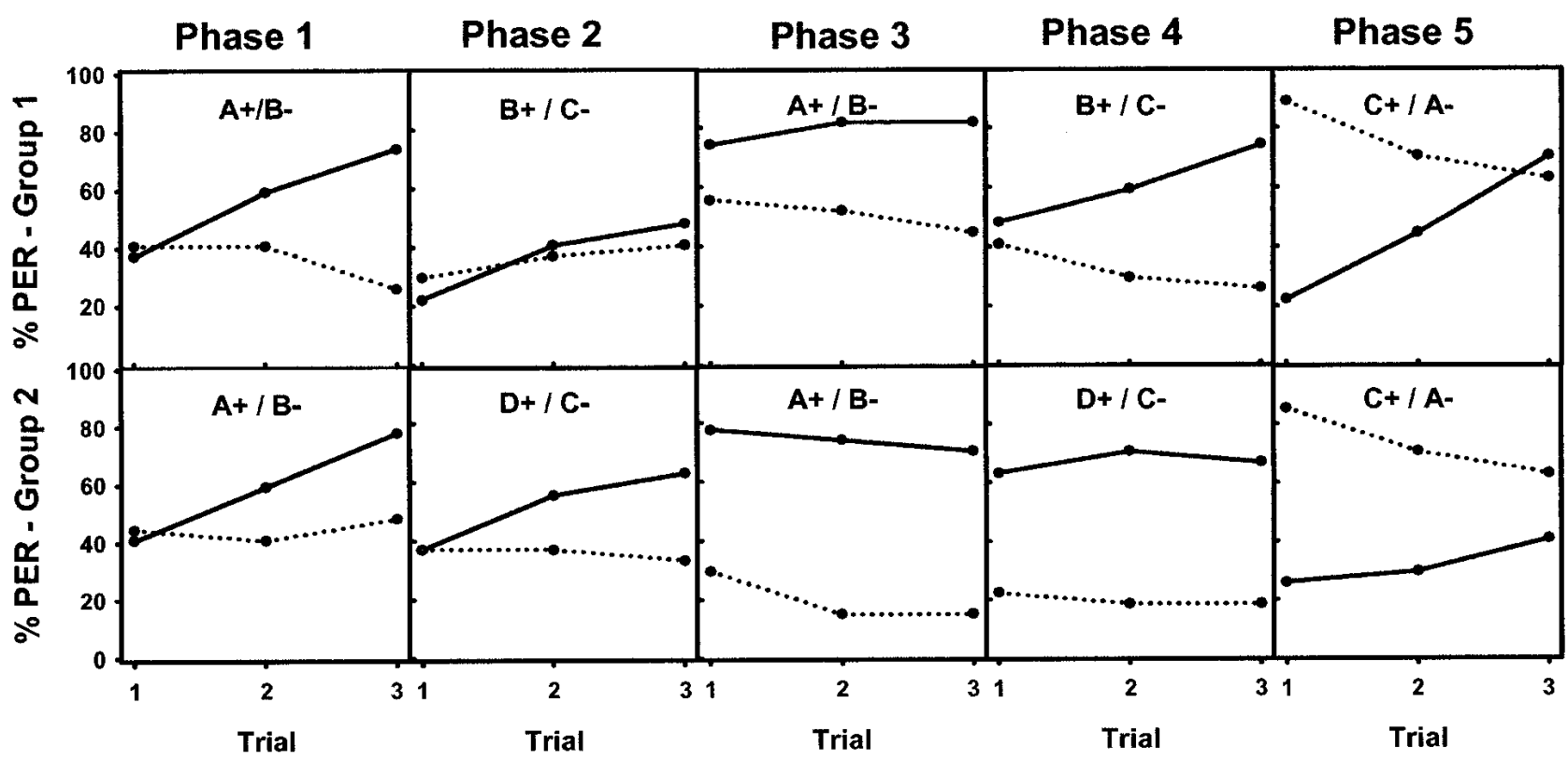

Figure 1 Experiment 1. Two groups of 27 bees (group 1, upper panel; group 2, lower panel) were differentially conditioned along five phases (shown in columns). Each phase had three CS+ presentations and three CS- presentations. For each phase (1 to 5), percent proboscis extension reflex (PER) along trials both for each CS+ and each CS - is shown. Bees of group 1 had a first B- $\rightarrow$ B + reversal from phase 1 to phase 2 , one $B+\rightarrow B$ - reversal from phase 2 to phase 3 , and a second $B-\rightarrow B+$ reversal from phase 3 to phase 4 previous to the last reversals $\left(\mathrm{C}-\rightarrow \mathrm{C}+\right.$ and $\left.\mathrm{A}_{+} \rightarrow \mathrm{A}-\right)$ of phase 5 . Bees of group 2 had no reversal experience before the start of phase 5 , which was the same for both groups.

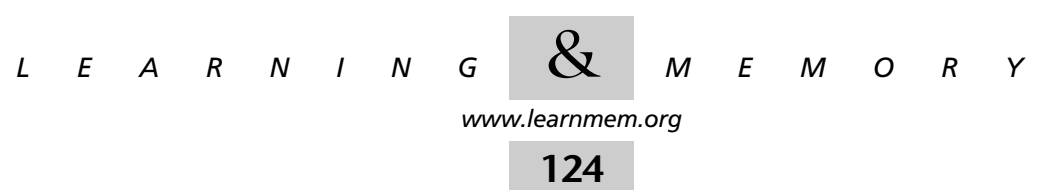


2). The last phase was identical for all three groups. In group 3 , bees were trained with two reversals $(\mathrm{B}-\rightarrow \mathrm{B}+$; $\mathrm{C}-\rightarrow \mathrm{C}+$ ). In group 4 , bees were trained with one reversal $(\mathrm{B}-\rightarrow \mathrm{B}+)$ and in group 5 with zero reversals. Within each phase, reinforced and nonreinforced odors were given three times and in a randomized sequence. Odors used were limonene, 2-octanol, nonanone, 2-heptanal, methylacetate, and eugenol (SIGMA). Previous experiments showed that bees could learn and discriminate these odors equally well. The experiment was designed such that fixed-odor pairs (limone and octanol, nonanone and heptanal, and eugenol and methylacetate) were balanced as successive and different conditioning pairs. Kruskal-Wallis test in phase 1 did not show significant differences between the six odors when these had a CS+ status $(H=5.66$; [degrees of freedom] df: 5; NS). But we found a significant difference between odors when they had a CS- status $(H=22.56$; df: 5; $P<0.001)$. Significance was introduced only by heptanal, which differed from all others odors $(H=12.48$; df: 1 ; $P<0.001)$. Bees showed spontaneous responses to heptanal before conditioning. Such spontaneous responses were not found in experiment 1 . This result had no influence on the main findings of our work because bees decreased their response to heptanal in the same amount as they did for the other odors (i.e., an $\sim 20 \%$ decrease in the third trial).

Before testing the impact of reversal pretraining, we checked whether or not the preconditions mentioned in experiment 1 were also met in experiment 2. Figure 2 shows the course of responding for group 3 (upper row), group 4 (middle row), and group 5 (lower row) throughout phase 1 to phase 4 (columns from left to right). As in experiment 1 , the groups did not differ in their ability to learn a discrimination between two stimuli (A+ vs. B-). In phase 1 , all three groups were directly comparable and showed successful response differentiation between $\mathrm{A}+$ and $\mathrm{B}-$ across trials. Starting from $\sim 0 \%$ and 30\% PER in trial 1 for $\mathrm{A}+$ and $\mathrm{B}-$, respectively, all three groups reached a comparable amount of differentiation in trial 3. This was confirmed by a $3 \times 2($ group $\times$ stimulus A/B) ANOVA for trial 3. The main effect stimulus was significant $\left(F_{1,93}=100.41 ; P<0.001\right)$, whereas the group $\times$ stimulus interaction was not significant $\left(F_{2,93}=1.51\right.$; NS). Figure 2 also shows that all groups showed comparable responses to A+ (phase 1, trial 3) and $\mathrm{D}-$ (phase 3, trial 3) before the last reversal learning ( $\mathrm{A}-$, $\mathrm{D}+$ ) in phase 4 . Comparing responses to $\mathrm{A}+$ in the last trial of phase 1 and to D- in the last trial of phase 4 by means of

\begin{tabular}{lcccc} 
Table 2. & Experiment 2 & & & \\
\hline Group & Phase 1 & Phase 2 & Phase 3 & Phase 4 \\
\hline 3 & A+ B- & B+ C- & C+ D- & D+ A- \\
4 & A+ B- & B+ C- & E+ D- & D+ A- \\
5 & A+ B- & F+ C- & E+ D- & D+ A- \\
\hline
\end{tabular}

ANOVA yielded $F<1$. Hence, the necessary conditions for evaluating the impact of prior reversals in phase 4 were met.

For the statistical evaluation of performance in phase 4, we again computed a learning score analogous to experiment $1\left(\Delta_{1}=\mathrm{A}-_{\text {trial } 1}-\mathrm{A}-_{\text {trial } 3} ; \Delta_{2}=\mathrm{D}+_{\text {trial } 3}-\mathrm{D}+_{\text {trial } 1}\right.$; $\Delta=\Delta_{1}+\Delta_{2}$ ). The resulting scores were $0.594,0.625$, and 0.281 for groups 3,4 , and 5 , respectively. To test the two rival hypotheses, a priori contrasts (see Rosenthal and Rosnow 1985) were used for focused comparisons in ANOVA. Under the assumption that the ability to reverse increases with increasing reversal pre-experience, the lambdas are 1 , 0 , and -1 for groups 3, 4, and 5, respectively. This focused comparison was not significant $\left(\mathrm{F}_{1,93}=3.49\right.$; NS). But under the assumption that one reversal is already enough and additional reversals do not improve reversal performance $(\lambda=0.5,0.5$, and -1$)$, this focused comparison was significant $\left(\mathrm{F}_{1,93}=5.12 ; P<0.03\right)$.

\section{DISCUSSION}

In experiment 1 we compared bees in a final reversal task consisting of two reversals. Before that final task, bees of group 1 had experienced three reversals, whereas bees of group 2 had experienced no reversal. Bees of group 1 were better in learning to reverse the contingencies than bees of group 2. In experiment 2 we manipulated the amount of pre-experience with reversals. Group 3 experienced two reversals, group 4 one reversal, and group 5 no reversal before all three groups had to learn two reversals in the final phase. The results showed that one prior reversal experience was enough to perform better in the final reversal task. The contrast analyses clearly supported the assumption that there were no differences between groups 3 and 4 with two previous reversals and one previous reversal, respectively, but that both were better than group 5 with no previous reversal. Although none of the three groups managed to revert its response in order to respond more to the CS+ than to the $\mathrm{CS}-$, it is conceivable that the CS+ versus CS- discrimination could appear after increasing the number of trials in groups 3 and 4 but not in group 5 . Indeed, results on single reversal learning with honeybees (Ferguson et al. 2001) conditioned with six instead of three learning trials showed that after three reversal-learning trials, bees still respond more to the CS- $(\sim 45 \%$ average performance; see Fig. 2) than to the CS+ ( $-35 \%$ average performance; see Fig. 2). Only by the fifth trial did bees start to respond significantly more to the CS+ than to the CS-.

Pre-experience with even one reversal thus affected further reversal learning. We therefore have to consider the possible learning strategies underlying our results. The bees cannot simply use the physical characteristic of the stimuli to predict the correct response because their predictive value with regard to reinforcement changes with successive reversals. Only bees of those groups in which no previous 


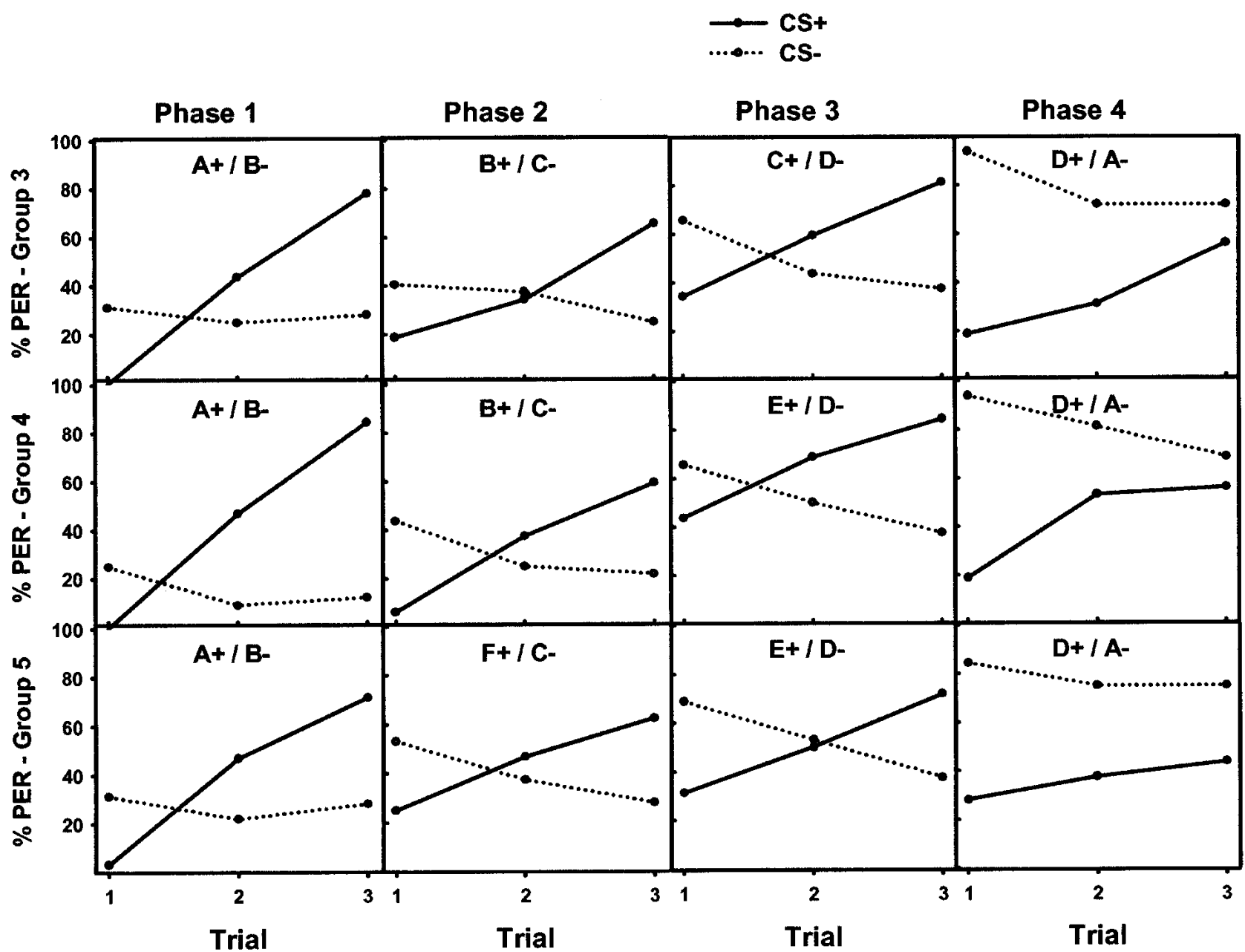

Figure 2 Experiment 2. Three groups of 32 bees (group 3, upper panel; group 4, middle panel; group 5, lower panel) were differentially conditioned along four phases (shown as columns). Each phase had three CS+ presentations and three CS- presentations. For each phase (1-4), percent PER along trials both for each CS+ and each CS- is shown. Bees of group 3 had a B- $\rightarrow B+$ reversal from phase 1 to phase 2 and a $C-\rightarrow C+$ reversal from phase 2 to phase 3 , previous to phase 4 in which two reversals were implied (D- $\rightarrow D+$ and $A+\rightarrow A-)$. Bees of group 4 had a single reversal $B-\rightarrow B+$ from phase 1 to phase 2, previous to phase 4 , in which two reversals were implied (D- $\rightarrow$ D+ and $\left.A_{+} \rightarrow A_{-}\right)$. Bees of group 5 had no reversal previous to phase 4 , in which two reversals were implied (D- $\rightarrow D_{+}$and $\left.A+\rightarrow A-\right)$.

reversal was performed (groups 2 and 5) could rely on the predictive stimulus value. Therefore, the animal could use the outcome of one trial to determine its response in the next one. This is compatible with a win-stay, lose-shift strategy, in which the subject's response shifts to an alternative stimulus following each nonreinforced response but remains with the previous response when reinforced. Perfect reversal performance using such a strategy would be reflected by only a single error on each reversal. This strategy cannot account for our results as performance in the second trial of the last phase of both experiments did not differ between those groups having reversal experience and those lacking it. If reversal experience has the consequence of promoting win-stay, lose-shift choice, we should be able to detect a significant difference between groups right after the first trial, in which the reinforcement contingencies were changed. Such a difference was never found in the second trial of both experiments.

Alternatively, bees may develop a configural learning strategy to cope with the successive reversal discriminations. They may learn each odor pair in terms of a unique configuration in which the specific odor combination determines the discrimination between $\mathrm{CS}+$ and $\mathrm{CS}-$. For instance, in experiment 1 , they may learn that in the context of $\mathrm{B}, \mathrm{A}$ is the reinforced odor, but in the context of $\mathrm{C}, \mathrm{A}$ is nonreinforced. Such a strategy would apply to each odor pair and is akin to strategies used to solve the so-called transverse-patterning problem (Sutherland and Rudy 1989; Alvarado and Rudy 1992). In such a problem, animals have to learn that when A and B are paired, A is correct; when B and $\mathrm{C}$ are paired, $\mathrm{B}$ is correct; and when $\mathrm{A}$ and $\mathrm{C}$ are paired, $\mathrm{C}$ is correct. The third of these discriminations is relatively

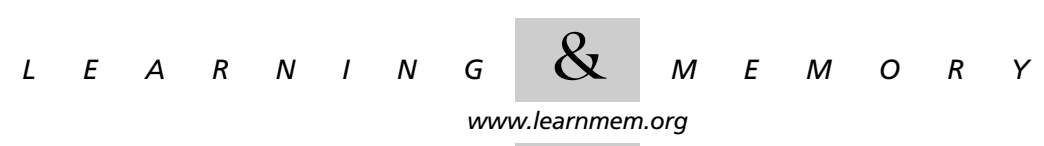


difficult to learn because the A versus $\mathrm{C}$ discrimination goes against a logical inference about what stimulus should be reinforced given that $\mathrm{A}$ is reinforced over $\mathrm{B}$ and $\mathrm{B}$ is reinforced over C. Although our experiments resemble such a design, they cannot be assimilated to the design because we do not know whether at the end of the experiment bees were able to respond correctly to all odor pairs simultaneously.

Our results do not distinguishing between a configural strategy such as that explained above, and the unique-cue hypothesis (Rescorla 1972, 1973; Whitlow and Wagner 1972). In the latter case, the elemental summation principle (a compound is the sum of its elements) is retained and, in addition to the explicitly administered elemental CSs, a supplementary (unobserved) CS is internally generated and eligible for being associated with the US. The unique-cue hypothesis is not a pure elemental theory as it has to assume the existence of an additional CS beyond those defined by the elements themselves. In accounting for results in which the distinction between configural and unique-cue-based strategies is not possible, it is cautious to conclude that results support nonelemental processing. The use of nonelemental processing has been shown in honeybees in the visual (Fauria et al. 2002; Schubert et al. 2002) and in the olfactory modality (Chandra and Smith 1998; Deisig et al. 2001). In the latter case, olfactory conditioning of PER was used. Bees were shown to solve a negative patterning discrimination $(\mathrm{A}+, \mathrm{B}+, \mathrm{AB}-)$, a fact that cannot be explained by pure elemental learning theories (Deisig et al. 2001). In our experiments bees were not presented with olfactory compounds. Nevertheless, configuring A and B with an expected outcome for $\mathrm{A}$ and a different outcome for $\mathrm{B}$ is possible and the same strategy could be applied to all odor pairs used. So far, we cannot decide whether bees in our experiments did indeed use a configural strategy. What seems, however, to happen is that successive reversal learning induces a learning-to-learn effect, its basis as yet unclear. Experiments aimed to find this basis have been performed in primates. Schusterman (1962) trained chimpanzees in 1300 trials to decide whether they adopt a win-stay, loseshift or a win-shift, lose-stay strategy in reversal learning. His results were consistent with a win-stay, lose-shift strategy. Such a large number of trials was used to introduce several reversals in which the animals experienced the inversion of contingencies. In our case, it is impossible to measure reliably the bees' performance in a training schedule involving several (more than five) phases. Firstly, bees received $3 \mu \mathrm{L}$ of sucrose solution at each reinforced trial (see Materials and Methods). An experiment involving six phases (one more than in our experiment 1) would have a total of 36 trials, half of which would be reinforced. Thus, bees would end up with $54 \mu \mathrm{L}$ and thus their responsiveness at the end of the training would be reduced as they would be satiated (the full crop-load capacity of a honeybee is $50 \sim 60 \mu \mathrm{L}$; see Núñez 1982). Secondly, many bees do not survive after long periods of immobilization under the conditions imposed by the PER paradigm. Thirdly, it may happen that bees generalize their response to all odors after extensive training.

Despite the absence of a mechanism explaining our results, we conclude that bees seem to learn to reverse. Another option that has to be considered, although it is remote, is that the differences found between the groups experiencing previous reversals and those experiencing no reversals was due to the latter learning to not reverse. In other words, bees without reversal experience would inhibit a natural tendency to learn to reverse. Presently, we cannot distinguish between these two options, although the latter is rather improbable.

The neurobiological basis of olfactory coding in the honeybee can yield some light on how bees solved the last reversals in our experiments. The basic principles of olfactory coding at the level of the bee antennal lobe, the primary olfactory neuropile in the insect brain, are now known (Galizia and Menzel 2000). The antennal lobe is a spherical structure with 160 glomeruli innervated by about 60,000 chemoreceptor axons. Optical recordings in vivo of the antennal lobe using calcium-sensitive fluorescent dyes during olfactory stimulation showed that odors are coded as specific spatio-temporal excitation patterns (Joerges et al. 1997). Specific ensembles of glomeruli represent odors in a combinatorial manner. Also differential conditioning of the PER with a reinforcing and a nonreinforcing odor was done in parallel with optical imaging studies of the antennal lobe. It was shown that the neural representation of a reinforced odor (CS+) becomes more pronounced and distinct from that of a nonreinforced odor (CS-), which has general features that do not change (Faber et al. 1999). Our results raise the question of the neural change implicated in successive reversal learning. If the neural activation pattern of a reinforced odor becomes more intense as a consequence of reinforcement, what happens to it when the bee relearns it as a nonreinforced stimulus? Does the neural pattern return to its original intensity level? Or does it change qualitatively? Such questions can be now answered on the basis of opto-physiological studies at the level of the bee brain (Galizia and Menzel 2000).

The foraging success of worker bees is an important component of colony fitness for honeybees (Oster and Wilson 1978; Seeley 1995). This success is closely related to the learning ability of worker (Menzel 1990, Menzel et al. 1993). As information about resources changes fast, worker bees must learn the new information to maximize colony productivity (Seeley 1994). Honeybees are "flower constant" (Grant 1951), which means that they temporarily specialize in the exploitation of one flower species as long as it is profitable. When food-source profitability changes, bees rapidly switch to another food source. As the very basis of

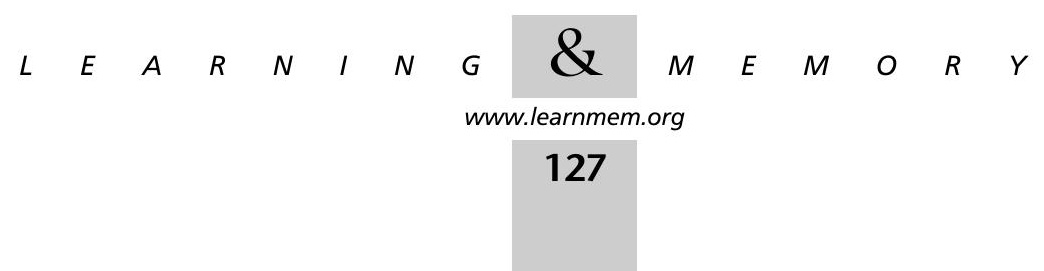


flower constancy is the learning capacity for the sensory cues that characterize the flower morph being exploited (Menzel 1985, Menzel et al. 1993), switching to another morph is related to reversal performances studied in our experiments. Under such circumstances different strategies could be applied to optimize foraging efficiency. One possibility is that shown by our work, namely improving the mastering of successive reversals. Another one is that found by Menzel (1969), who studied multiple reversal learning in free-flying honeybees trained with two colors. He found that after three reversals bees chose both colors at a $50 \%$ level. The result of the multiple reversal experience was thus a generalization of the choice performance, such that bees chose both colors equally at the end of the training procedure. Such a result was not observed in our case as we found an improvement of reversal learning caused by successive reversals. The successive different reversals trained in our experiments resemble the natural foraging situation, in which a honeybee forager has to switch successively from a species initially exploited to different ones. The fact that experiencing such changes seems to improve its performance in dealing with further new exploited food sources has therefore an adaptive impact for the individual and for the colony as a whole.

\section{MATERIALS AND METHODS}

\section{Subjects}

Free-flying honeybee foragers, Apis mellifera, were caught at the entrance of outdoor hives every morning of each experimental day. They were placed in small glass vials and cooled in ice until they ceased their movements. The bees were then harnessed in small metal tubes such that they could only move their antennae and mouthparts, including the proboscis (Takeda 1961; Bitterman et al. 1983). Subsequently, bees were fed with $4 \mu \mathrm{L}$ of a sucrose solution $(30 \% \mathrm{w} / \mathrm{w})$ and kept in the dark and high humidity for $2 \mathrm{~h}$. Fifteen minutes before starting the experiments, each subject was checked for intact proboscis extension reflex (PER) by lightly touching one antenna with a toothpick soaked with sucrose solution without subsequent feeding. Extension of the proboscis beyond a virtual line between the open mandibles was counted as PER (unconditioned response). Animals that did not show the reflex $(<5 \%)$ were discarded.

\section{Unconditioned and Conditioned Stimuli}

The US was $30 \%$ sucrose solution. The CSs were the odorants chosen for the different experiments (see Results). On each experimental day, $4 \mu \mathrm{L}$ of pure odorant were applied onto a fresh strip of filter paper. The paper strips were then placed into a 1-mL plastic syringe and mounted in an odor-supplying device. When the bee was placed in front of the device, it received a gentle, constant flow of clean air provided by a standard aquarium pump. Computerdriven solenoid valves (Lee Company) controlled airflow delivery. During periods of odorant delivery, the airflow was shunted through a syringe containing the odorant. An exhaust system was mounted behind the bees to remove odor-laden air.

\section{Training}

Each trial lasted $60 \mathrm{sec}$. At the beginning of each trial the subject was placed in front of the odor-supplying device for $26 \mathrm{sec}$ to allow familiarization with the training situation. Thereafter the CS was presented for $4 \mathrm{sec}$. In reinforced trials, the US onset occurred $3 \mathrm{sec}$ after CS onset. Both antennae were lightly touched with a toothpick soaked with the sucrose solution and after proboscis extension the bee was allowed to feed for $3 \sec (\sim 3 \mu \mathrm{L}$ of sucrose solution). Therefore, the interstimulus interval was $3 \mathrm{sec}$ and the overlap between CS and US was 1 sec. After completing each 60sec trial, animals were returned to their resting position. Differential conditioning was used in all experiments. In such conditioning, animals have to learn to respond to the reinforced odor (CS+) and not to the nonreinforced odor (CS-). Nonreinforced trials consisted of CS presentations without US. The intertrial interval was 6 min. Such an interval concerns trials and not trial types (CS+ or CS-). The sequence of CS+ and CS- trials was randomized within each experimental phase and also varied from one day to the next. At most, two reinforced/nonreinforced trials succeeded each other within one conditioning phase. Depending on the experiment (see above) the successive differential conditioning phases did or did not involve reversal discrimination. As the sequence of CS+ and CS- trials was randomized within each experimental phase, a reversal from a CS- to a CS+ could be detected either immediately (e.g., the last trial of the previous phase being a CS- one and first trial of the next phase being a CS+ one) or after a certain number of intercalated trials varying from one to four.

\section{Response Measurement}

We recorded whether or not a bee extended its proboscis within 3 sec after onset of the odor (CS). Responses in this interval cannot be elicited directly by the US. Hence we measured anticipatory responding. Multiple responses during a CS were counted as a single PER. After completing the experiments, all animals were again checked for proboscis extension reflex. If an animal did not respond $(<5 \%)$, it was discarded.

\section{Statistical Analysis}

We measured the percentage of conditioned responses (percent PER) in CS+ and CS- trials. ANOVAs were used for between-group and within-group comparisons. Although parametric ANOVA is usually not allowed in case of dichotomous data such as those of the PER, Monte Carlo studies have shown that it is permissible to use ANOVA for a dichotomous dependent variable under certain conditions (Lunney 1970), which are met by the experiments reported here (equal cell frequencies and at least 40 degrees of freedom of the error term). When these conditions were not met, Kruskal-Wallis tests were used. A priori contrasts (see Rosenthal and Rosnow 1985) were used for focused comparisons in the statistical evaluation of the rival hypotheses in experiment 2 . The alpha level was set to 0.05 (two-tailed) for all analyses.

\section{ACKNOWLEDGMENTS}

We thank Randolf Menzel for comments on an earlier version of the manuscript and for helpful discussions and encouragement. We also thank the comments of two anonymous referees. This work was supported by the special program SFB 515 of the National German Science Foundation (grant C7 to M.G. and D.M.). M.G. acknowledges the support of the Human Frontier Science Program, the program Action Cognitique 2001 (French Research Ministry), and the Fondation pour la Recherche Médicale. H.L. acknowledges the support of the National German Science Foundation (grants DFG La 564/10-1 and DFG La 564/10-3).

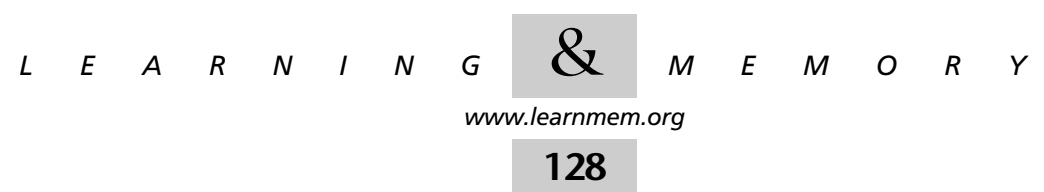


The publication costs of this article were defrayed in part by payment of page charges. This article must therefore be hereby marked "advertisement" in accordance with 18 USC section 1734 solely to indicate this fact.

\section{REFERENCES}

Alvarado, M.C. and Rudy, J.W. 1992. Some properties of configural learning: An investigation of the transverse-patterning problem. $J$. Comp. Psychol. 18: 145-153.

Ben-Shahar, Y., Thompsom, C.K., Hartz, S.M., Smith, B.H., and Robinson, G.E. 2000. Differences in performance on a reversal learning test and division of labor in honeybee colonies. Anim. Cogn. 3: 119-125.

Bitterman, M.E. 1975. The comparative analysis of learning. Science 188: 699-709.

. 1996. Comparative analysis of learning in honeybees. Anim. Learn. Behav. 24: 123-141.

Bitterman, M.E., Menzel, R., Fietz, A., and Schäfer, S. 1983. Classical conditioning of proboscis extension in honeybees (Apis mellifera). $J$. Comp. Psychol. 97: 107-119.

Chandra, S. and Smith, B.H. 1998. An analysis of synthetic processing of odor mixtures in the honeybee (Apis mellifera). J. Exp. Biol. 201: 3113-3121.

Davey, G. 1989. Ecological learning theory. Routledge, London.

Deisig, N., Lachnit, H., Giurfa, M., and Hellstern, F. 2001. Configural olfactory learning in honeybees: Negative and positive patterning discrimination. Learn. Mem. 8: 70-78.

Faber, T., Joerges, J., and Menzel, R. 1999. Associative learning modifies neural representations of odors in the insect brain. Nat. Neurosci. 2: $74-78$.

Fauria, K., Dale, K., Colborn, M., and Collett, T.S. 2002. Learning speed and contextual isolation in bumblebees. J. Exp. Biol. 205: 1009-1018.

Ferguson, H.J., Cobey, S., and Smith, B. 2001. Sensitivity to a change in reward is heritable in the honeybee, Apis mellifera. Anim. Behav. 61: 527-532.

Galizia, C.G. and Menzel, R. 2000. Odour perception in honeybees: Coding information in glomerular patterns. Curr. Opin. Neurobiol. 10: $504-510$.

Grant, V. 1951. The fertilization of flowers. Sci. Amer. 12: 1-6.

Hammer, M. 1997. The neural basis of associative reward learning in honeybees. Trends in Neurosci. 20: 245-252.

Hammer, M. and Menzel, R. 1995. Learning and memory in the honeybee. J. Neurosci. 15: 1617-1630.

Hosler, J.S., Chandra, S.B., and Smith, B.H. 2000. Heritable variation for latent inhibition and its correlation to reversal learning in the honeybee, Apis mellifera. J. Comp. Psych. 114: 86-97.

Joerges, J., Küttner, A., Galizia, C.G., and Menzel, R. 1997. Representations of odors and odor mixtures visualized in the honeybee brain. Nature 387: 285-288

Lunney, G.H. 1970. Using analysis of variance with a dichotomous dependent variable: An empirical study. J. Educat. Meas. 7: 263-269.

Menzel, R. 1969. Das Gedächtnis der Honigbiene für Spektralfarben. II. Umlernen und Mehrfachlernen. Z. vergl. Physiol. 63: 290-309.

. 1985. Learning in honeybees in an ecological and behavioral context. In Experimental behavioral ecology (eds. B. Hölldobler and M. Lindauer), pp. 55-74. Fischer, Stuttgart, Germany.

1990. Learning, memory and 'cognition' in honeybees. In
Neurobiology of comparative cognition (eds. R.P. Kesner and D.S. Olton), pp. 237-292. Erlbaum, Hillsdale, NJ.

Menzel, R. and Müller, U. 1996. Learning and memory in honeybees: From behavior to neural substrates. Annu. Rev. Neurosci. 19: 379-404.

Menzel, R. and Giurfa, M. 2001. Cognitive architecture of a minibrain: The honeybee. Trends in Cognitive Sciences 5: 62-71.

Menzel, R., Greggers, U., and Hammer, M. 1993. Functional organization of appetitive learning and memory in a generalist pollinator, the honeybee. In Insect learning: Ecological and evolutionary perspectives (eds. D. Papaj and A.C. Lewis), pp. 79-125. Chapman and Hall, New York.

Núñez, J.A. 1982. Honeybee foraging strategies at a food source in relation to its distance from the hive and the rate of sugar flow. J. Apic. Res. 21: 139-150.

Oster, G.F. and Wilson, E.O. 1978. Caste and ecology in the social insects. Princeton University Press, Princeton, NJ.

Pavlov, I.P. 1927. Lectures on conditioned reflexes. International Publishers, New York.

Pearce, J.M. 1994. Similarity and discrimination: A selective review and a connectionist model. Psychol. Rev. 101: 587-607.

Rescorla, R.A. 1972. "Configural" conditioning in discrete-trial bar pressing. J. Comp. Physiol. Psychol. 79:307-317.

- 1973. Evidence for "unique stimulus" account of configural conditioning. J. Comp. Physiol. Psychol. 85:331-338.

Rescorla, R.A. and Wagner, A.R. 1972. A theory of Pavlovian conditioning: Variations in the effectiveness of reinforcement and nonreinforcement. In Classical conditioning 2: Current research and theory (eds. A.H. Black and W.F. Prokasy), pp. 64-99. Appleton-Century-Crofts, New York.

Rosenthal, R. and Rosnow, R.L. 1985. Contrast analysis: Focused comparisons in the analysis of variance. Cambridge University Press, Cambridge, UK.

Rudy, J.W. and Sutherland, R.J. 1995. Configural association theory and the hippocampal formation: An appraisal and reconfiguration. Hippocampus 5: 375-389.

Seeley, T.D. 1994. Honeybee foragers as sensory units of their colonies Behav. Ecol. Sociobiol. 34: 51-62.

-1995. The wisdom of the hive-The social physiology of honeybee colonies. Harvard University Press, London.

Smith, B.H. 1991. The olfactory memory of the honeybee Apis mellifera. I. Odorant modulation of short- and intermediate-term memory after single-trial conditioning. J. Exp. Biol. 161: 367-382.

Smith, B.H. and Cobey, S. 1994. The olfactory memory of the honeybee Apis mellifera. II. Blocking between odorants in binary mixtures. J. Exp. Biol. 195: 91-108.

Sutherland, R.J. and Rudy, J.W. 1989. Configural association theory: The contribution of the hippocampus to learning, memory, and amnesia. Psychobiology 17: 129-144.

Takeda, K. 1961. Classical conditioned response in the honeybee. J. Insect Physiol. 6: 168-179.

Whitlow, J.W. and Wagner, A.R. 1972. Negative patterning in classical conditioning: Summation of response tendencies to isolable and configural components. Psychonom. Sci. 27: 299-301.

Received October 22, 2001; accepted in revised form March 28, 2002.

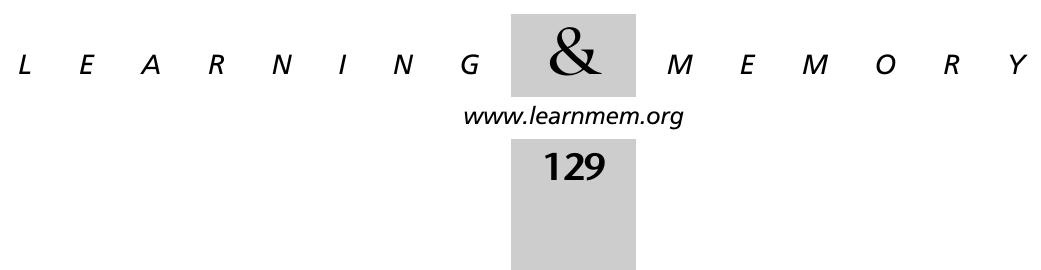




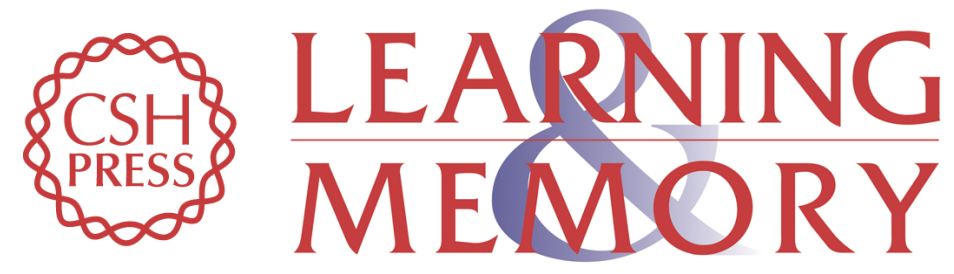

\section{Successive Olfactory Reversal Learning in Honeybees}

Bernhard Komischke, Martin Giurfa, Harald Lachnit, et al.

Learn. Mem. 2002, 9:

Access the most recent version at doi:10.1101/lm.44602

References This article cites 24 articles, 7 of which can be accessed free at: http://learnmem.cshlp.org/content/9/3/122.full.html\#ref-list-1

License

Email Alerting Receive free email alerts when new articles cite this article - sign up in the box at the Service top right corner of the article or click here. 